\title{
Colorectal endoscopic submucosal dissection by using latex-band traction
}

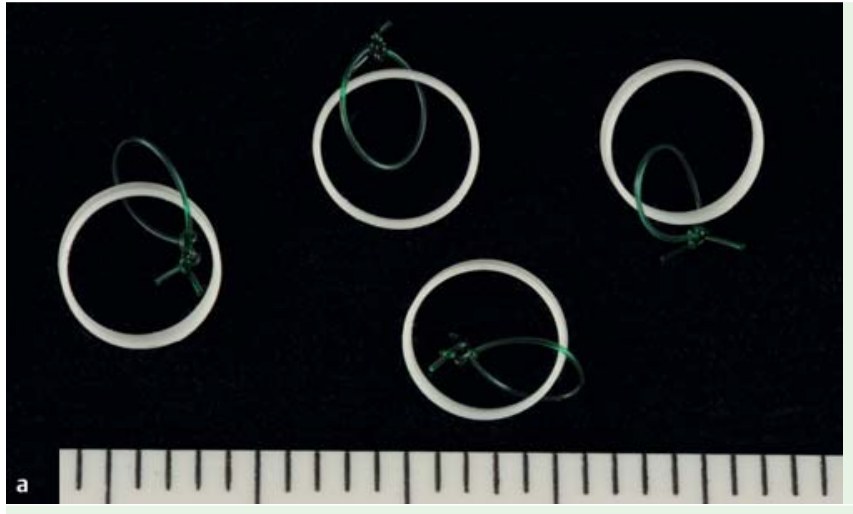

Fig. 1 A medical rubber band, named the "Latex Band," which is $5 \mathrm{~mm}$ in diameter, $1 \mathrm{~mm}$ in width, and $200 \mu \mathrm{m}$ in thickness. a The green nylon thread was passed through the latex band and looped. $\mathbf{b}$ The latex band was attached to the endoclip arm. c The endoclip was set in a pair of forceps.
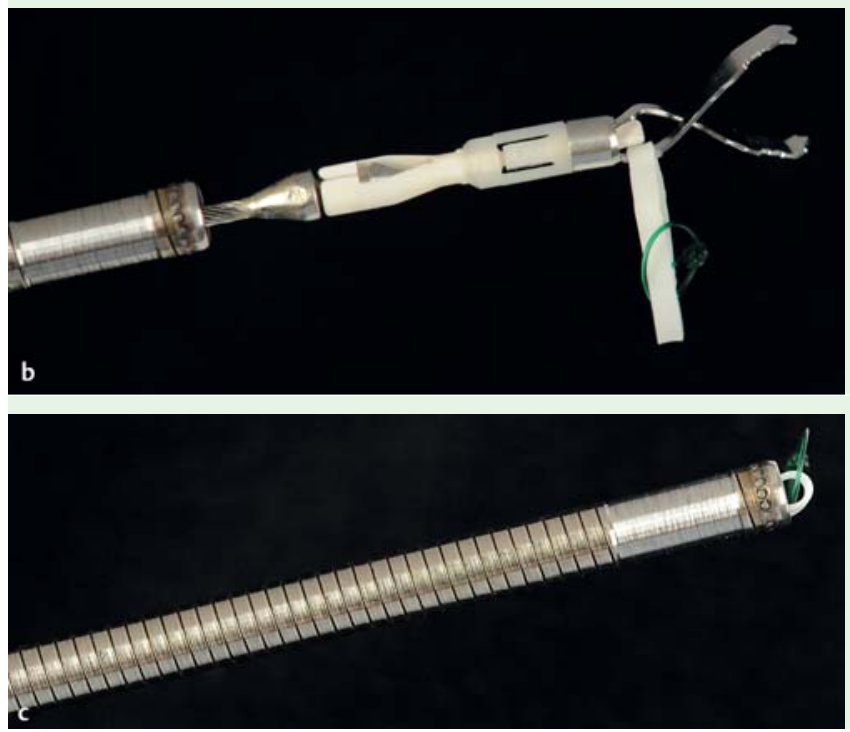

Traction can help reduce the risk of complications in colorectal endoscopic submucosal dissection (ESD) [1,2]. We have developed a latex-band traction system for colorectal ESD [2]. Traction uses a medical rubber band, named the "Latex Band," which is $5 \mathrm{~mm}$ in diameter, $1 \mathrm{~mm}$ in width, and $200 \mu \mathrm{m}$ in thickness (Okamoto Co. Ltd., Tokyo, Japan). The 4- 0 green nylon thread was passed through a latex band and looped ( Fig. 1a). The latex band was attached to the endoclip arm (Olympus, Tokyo, Japan) ( Fig.1 b). The endoclip was then set in a pair of forceps ( $\bullet$ Fig. 1 c). After circumferential incision was completed, the latex band was attached to the edge of the exfoliated mucosa of the lesion by using an endoclip ( $\bullet$ Fig. 2 a). The nylon thread looped through the latex band was hooked on one of the arms of the endoclip. The nylon thread was clipped to the region of the intestinal wall opposite to the lesion. The lesion was pulled away from the muscle layer. Through this maneuver, sufficient space for clear visualization of the submucosal layer was obtained (॰ Fig. 2b).

Before the dissection was started, sodium hyaluronate solution was injected into the submucosal layer. Then, submucosal dissection was carried out.

After the lesion was resected, the specimen hanging from the opposite intestinal wall was cut off. Since the rubber latex band could not be cut with the electric current, the nylon thread was cut with the electric surgical knife to collect the specimen ( $\nabla$ Fig. 2c). After the resected specimen was collected, the endoclip was removed with great caution.

Traction using the Latex Band can be applied to any location in the colorectum. When traction is used, the space for the submucosal layer is widened, providing a
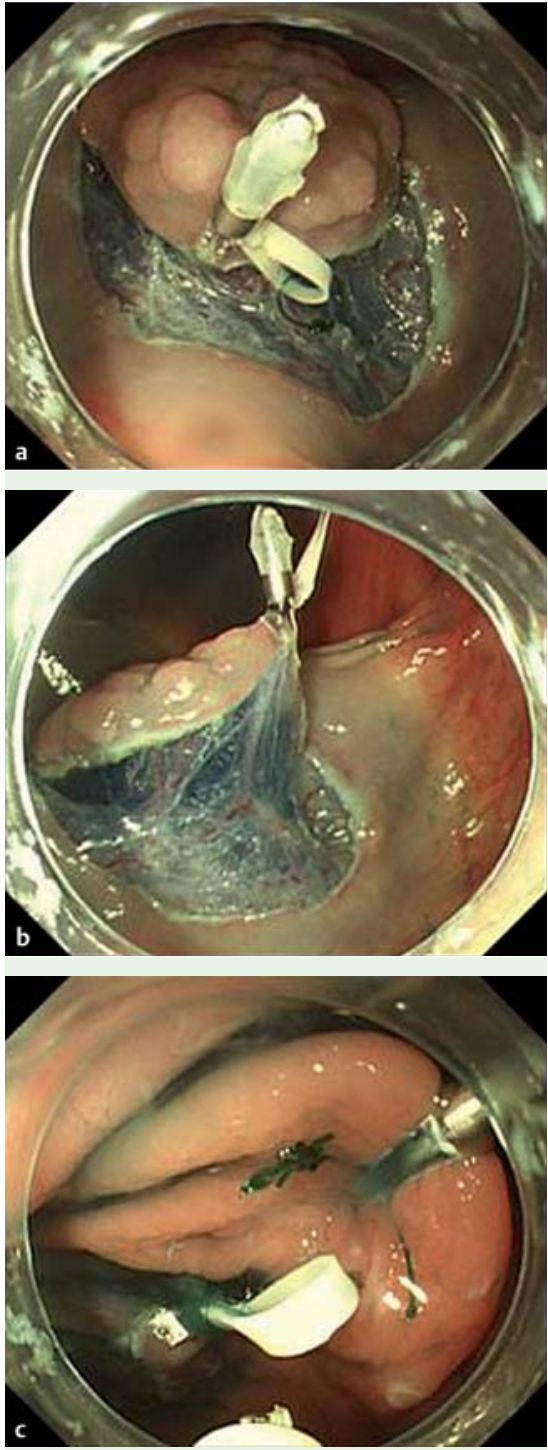

Fig. 2 a The endoclip attached to the edge of the exfoliated mucosa of the anal side of the lesion. $\mathbf{b}$ The green nylon thread looped through the latex band was clipped to the region of the intestinal wall opposite the lesion. The space for the submucosal layer was widened. c After the lesion was resected, the green nylon thread was cut with an electric surgical knife to collect the specimen.

clear view of the incision line. In conclusion, we consider that the Latex Band is a simple and noninvasive tool for tractionassisted colorectal ESD.

Endoscopy_UCTN_Code_TTT_1AQ_2AD

Competing interests: None 
Y. Tomiki, S. Ishiyama, K. Sugimoto, M. Takahashi, Y. Kojima, M. Tanaka, K. Sakamoto

Department of Coloproctological Surgery, Faculty of Medicine, Juntendo University, Tokyo, Japan

\section{References}

1 Saito Y, Sakamoto T, Fukunaga S et al. Endoscopic submucosal dissection (ESD) for colorectal tumors. Dig Endosc 2009; 21: S7-S12

2 Sakamoto N, Osada T, Shibuya T et al. The facilitation of a new traction device (S-O clip) assisting endoscopic submucosal dissection for superficial colorectal neoplasms. Endoscopy 2008; 40: E94-E95

\section{Bibliography}

DOI $10.1055 / \mathrm{s}-0030-1256462$

Endoscopy 2011; 43: E250-E251

(c) Georg Thieme Verlag KG Stuttgart · New York . ISSN 0013-726X

\section{Corresponding author}

Y. Tomiki, MD

Department of Coloproctological Surgery

Faculty of Medicine

Juntendo University

2-1-1 Hongo

Bunkyo-ku

Tokyo 113-8421

Japan

Fax: +81-3-38130731

tomiki@juntendo.ac.jp 